\title{
Some clinical pharmacological studies with indoramin, with observations on its therapeutic usefulness
}

\author{
C. DE B. WhITE \\ M.R.C.P.
}

\author{
P. TURNER \\ M.D., F.R.C.P. \\ M.R.C.P.
}

R. B. ROYDS

\author{
Department of Clinical Pharmacology, \\ St Bartholomew's Hospital, London
}

\begin{abstract}
Summary
In the treatment of fifteen patients with essential hypertension, in open trial indoramin caused a mean blood pressure fall from $180 / 115 \mathrm{mmHg}$ to $159 / 98$ mmHg. No reversal of antihypertensive effect was seen in four patients after additions of the tricyclic antidepressant drug desipramine. Blood pressure did not begin to rise in these four patients for at least 5 weeks after stopping indoramin. The implications of these findings are discussed.
\end{abstract}

\section{Introduction}

Indoramin (3-[2-(4-benzamidopiperid-1-yl)ethyl] indole) has been shown in animal experiments to combine competitive $\alpha$-adrenoceptor blocking properties with cardioinhibitory, local anaesthetic, antihistamine and anti-5-hydroxytryptamine activity (Alps et al., 1972; Collis and Alps, 1973). Its competitive $\alpha$-adrenoceptor blocking activity has been confirmed in studies of human isolated smooth muscle strips (Variava and Turner, 1973). Royds, Coltart and Lockhart (1972) showed that in healthy volunteers a single oral dose produced a significant fall in blood pressure when compared with placebo, and that after intravenous infusion of indoramin the pressure response to noradrenaline showed a parallel time-related shift to the right. Indoramin also produced a dose-dependent reduction in histamineinduced skin weals, but did not influence critical flicker frequency in doses which had $\alpha$-adrenoceptor blocking and antihistamine activity. Boakes, Prichard and Teoh (1972) found considerable positional falls in blood pressure after intravenous and oral dosing.

Preliminary clinical studies of indoramin in patients with essential hypotension indicated that it might have a therapeutic effect in this condition (Royds, 1972), although not all patients responded favourably in a recent study (Lewis, George and Dollery, 1973).

The hypotensive action of several established antihypertensive drugs, including bethanidine and guanethidine (Mitchell et al., 1970) and clonidine
(Briant, Reid and Dollery, 1973), is impaired by treatment with tricyclic antidepressant drugs. Since depression is not uncommon in patients who are being treated for essential hypertension, these interactions are of importance. Simpson and Waal-Manning (1971) suggested that in these circumstances a thiazide diuretic combined with a $\beta$-adrenoceptor blocking drug is the regimen of choice, but pointed out the lack of alternatives if those drugs were not effective or suitable.

It seemed reasonable, therefore, to investigate the interaction of indoramin with a tricyclic antidepressant drug. The results of such a study in four patients are described in this paper, together with a review of our clinical experience with indoramin in the treatment of essential hypertension.

\section{Methods \\ Open study: indoramin in essential hypertension}

Fifteen patients were treated with indoramin in open clinical trial. The patients had either not previously been treated for hypertension, or their blood pressure had not been adequately controlled with conventional treatment. In each case the diagnosis of essential hypertension was established by finding a raised diastolic blood pressure of greater than $105 \mathrm{mmHg}$ on at least two occasions after supine rest for $5 \mathrm{~min}$. Known causes of hypertension were excluded. Some patients, including patients 1 and 2 (Table 1), had repeated blood pressure readings as day patients in hospital.

\section{Influence of desipramine on the antihypertensive effect of indoramin \\ Of the patients who responded to indoramin, four were selected with mild degrees of depression. The addition of a medicine affecting mood was discussed with them, pointing out that although it might affect their blood pressure control they would be kept under close observation. Consent was freely given by each subject.}




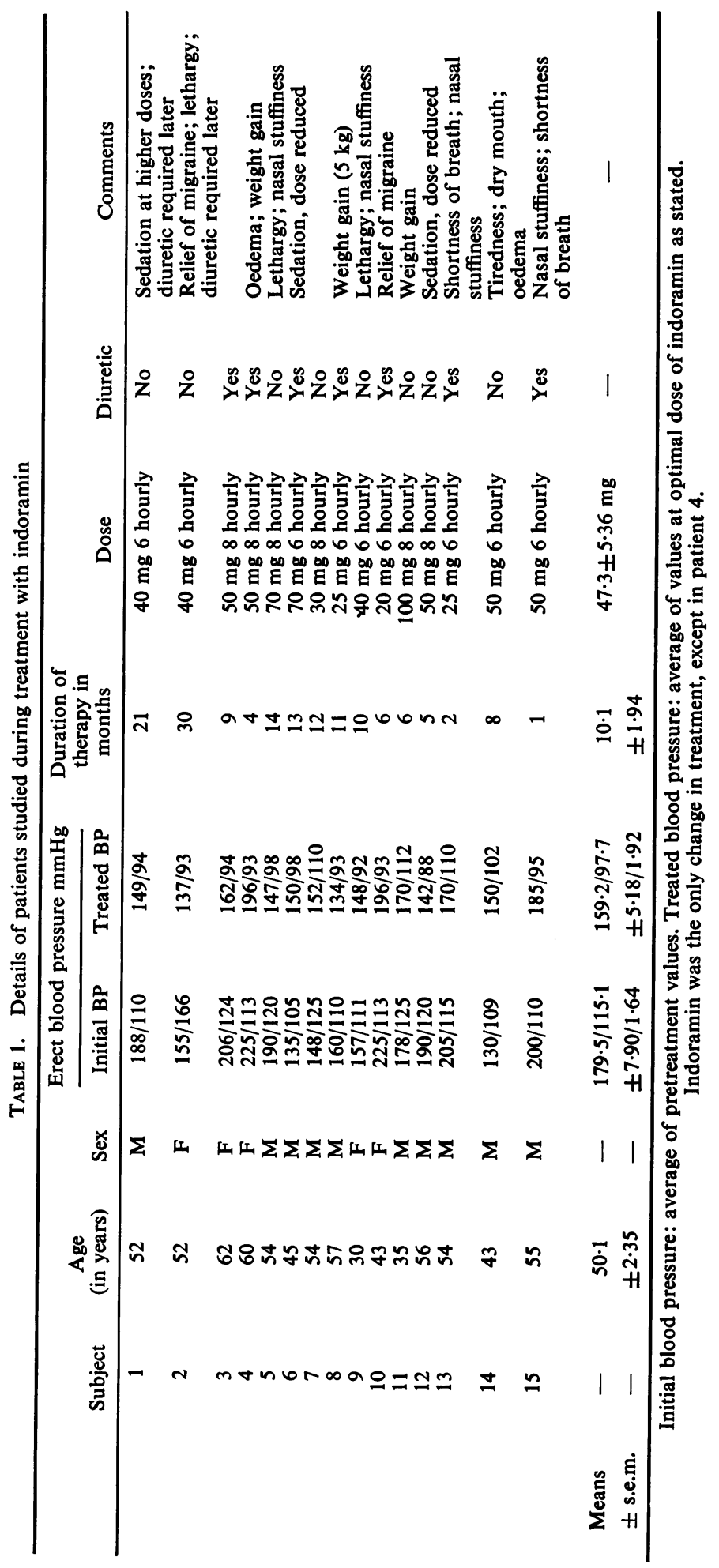


Two control blood pressure readings were made in the week before starting the study. Desipramine $25 \mathrm{mg} 8$ hourly or an identical placebo were added to the antihypertensive therapy in double blind manner in each patient for a period of 10 days. There was then a wash-out period of 4 days before crossover of medication and the commencement of the second 10-day treatment course. Two patients received desipramine first and the other two placebo.

All four patients were assessed on days 1, 2, 4, 7, $10,14,15,18,21,24$ and 28 of the investigation, at the same time of day. On each occasion, the blood pressure was measured with a London School of Hygiene sphygmomanometer after 5 min supine rest and again after 3 min standing. The pulse rate and any volunteered side effects were also recorded.

Mean blood pressures (diastolic $+1 / 3$ pulse pressure) during the two treatment periods were subtracted from the control pressures taken before the addition of antidepressant or its placebo. The difference between the means of changes in both treatment periods was calculated and compared using Student's ' $t$ ' test for differences between means.

\section{Effect of substitution of indoramin by placebo}

At the end of the study, active drug treatment was abruptly withdrawn from the four patients to confirm the diagnosis of hypertension. Indoramin therapy was replaced by identical placebo in a single blind fashion. The blood pressure was monitored at twice weekly and later at weekly intervals.

\section{Results}

\section{Open study: indoramin in essential hypertension}

The details of the patients and responses to treatment are given in Table 1 . The treated blood pressure values are the means of readings at the optimal dose of indoramin as quoted for each patient, the only change in treatment being the addition of indoramin. Some patients had previously been stabilized on thiazide diuretics which were continued unchanged throughout. In some patients who were not well controlled with indoramin alone, a thiazide diuretic was later found to have a marked additive effect.

The response to indoramin was variable. The mean reduction in standing blood pressure from pretreatment values for all patients was from $180 / 115 \mathrm{mmHg}$ to $159 / 98 \mathrm{mmHg}$ (Table 1). Continued increase in dosage where necessary was often limited by sedation and on one occasion by intolerable nasal stuffiness. Other side effects were dry mouth, weight gain, shortness of breath (two cases), ankle oedema (one case) and failure of ejaculation (one case). Sedation was usually seen at doses higher than 150 $\mathrm{mg} /$ day, but was reported after a single dose as low as $12.5 \mathrm{mg}$ in one patient.

No patient complained of palpitations while taking indoramin, though an increase in heart rate of up to 8 beats/min was often observed after starting therapy.

\section{Influence of desipramine on the antihypertensive effect of indoramin}

Table 2 shows that the blood pressure of the four patients in this study was well controlled by indoramin. The addition of desipramine to the treatment regimen did not adversely affect the action of indoramin. The mean blood pressure during treatment with indoramin plus desipramine in fact fell slightly by $7.9 \mathrm{mmHg}$ in the supine position and $11.7 \mathrm{mmHg}$ when erect. With indoramin plus placebo the mean blood pressure fell by $4.4 \mathrm{mmHg}$ in the supine and $4.1 \mathrm{mmHg}$ in the erect position. None of these changes was significantly statistically different from the blood pressure on indoramin alone.

Mean pulse rates for the four subjects during the placebo with indoramin period and the desipramine period were 86 beats/min and 89 beats/min standing and 82 beats/min in both periods lying down. The only side effects reported were of marked dryness of

TABLE 2. Blood pressures of four patients before and during treatment with indoramin, indoramin plus desipramine, and indoramin plus placebo

\begin{tabular}{|c|c|c|c|c|c|c|c|c|}
\hline \multirow[b]{3}{*}{ Patient } & \multicolumn{8}{|c|}{ Mean blood pressure (diast. $+1 / 3$ pulse) $(\mathrm{mmHg})$} \\
\hline & \multicolumn{2}{|c|}{ Before indoramin } & \multicolumn{2}{|c|}{$\begin{array}{c}\text { Controlled } \\
\text { on indoramin* }\end{array}$} & \multicolumn{2}{|c|}{$\begin{array}{l}\text { Indoramin } \\
+ \text { placebot }\end{array}$} & \multicolumn{2}{|c|}{$\begin{aligned} & \text { Indoramin } \\
+ & \text { desipramine } \dagger\end{aligned}$} \\
\hline & Supine & Erect & Supine & Erect & Supine & Erect & Supine & Erect \\
\hline $\begin{array}{l}1 \\
2 \\
3 \\
4\end{array}$ & $\begin{array}{l}131 \cdot 0 \\
119 \cdot 3 \\
154 \cdot 6 \\
152 \cdot 0\end{array}$ & $\begin{array}{l}136 \cdot 0 \\
129 \cdot 0 \\
151 \cdot 3 \\
150 \cdot 3\end{array}$ & $\begin{array}{r}107 \cdot 7 \\
91 \cdot 3 \\
124 \cdot 7 \\
128 \cdot 0\end{array}$ & $\begin{array}{r}99 \cdot 3 \\
83 \cdot 3 \\
120 \cdot 6 \\
127 \cdot 7\end{array}$ & $\begin{array}{r}104 \cdot 7 \\
95 \cdot 3 \\
111 \cdot 3 \\
122 \cdot 7\end{array}$ & $\begin{array}{r}94 \cdot 3 \\
88 \cdot 7 \\
110 \cdot 3 \\
121 \cdot 3\end{array}$ & $\begin{array}{r}100 \cdot 7 \\
92 \cdot 0 \\
122 \cdot 3 \\
105 \cdot 0\end{array}$ & $\begin{array}{r}96 \cdot 0 \\
76 \cdot 7 \\
109 \cdot 7 \\
101 \cdot 7\end{array}$ \\
\hline $\begin{array}{l}\text { Average } \\
\pm \text { s.e.m. }\end{array}$ & $\begin{array}{r}139 \cdot 2 \\
\pm 8 \cdot 49\end{array}$ & $\begin{array}{r}141 \cdot 6 \\
\pm 5 \cdot 48\end{array}$ & $\begin{array}{r}112 \cdot 9 \\
\pm 8 \cdot 47\end{array}$ & $\begin{array}{r}107 \cdot 7 \\
\pm 10 \cdot 13\end{array}$ & $\begin{array}{r}108 \cdot 5 \\
\pm 5 \cdot 76\end{array}$ & $\begin{array}{r}103 \cdot 6 \\
\pm 7 \cdot 45\end{array}$ & $\begin{array}{r}105 \cdot 0 \\
\pm 6 \cdot 37\end{array}$ & $\begin{array}{r}96.0 \\
\pm 7.03\end{array}$ \\
\hline
\end{tabular}

* Average of two readings.

$\dagger$ Average blood pressure over 10-day period. 
the mouth (two subjects), which ceased 5 days after stopping the desipramine, and drowsiness 2-3 hr after taking the tablets (one subject).

\section{Effect of substitution of indoramin by placebo}

When patients treated for long periods with indoramin had placebo substituted for this drug, blood pressure tended to remain low for prolonged intervals.

In patient 2, mean lying and standing blood pressures were 94 and $96 \mathrm{mmHg}$ respectively after 20 weeks of placebo substitution. Patients 1 and 4 maintained satisfactory mean pressures for 7 and 9 weeks respectively on placebo. The mean standing blood pressure of patient 1 rose to $112 \mathrm{mmHg}$ at week 10 and that of patient 4 to $146 \mathrm{mmHg}$ at week 15 , when both were restarted on indoramin there were subsequent falls to mean pressures of $106 \mathrm{mmHg}$ for patient 1 and $132 \mathrm{mmHg}$ for patient 2 . The mean standing blood pressure of patient 3 remained controlled for 4 weeks on placebo, then rose from 123 $\mathrm{mmHg}$ to $145 \mathrm{mmHg}$ by the seventh week, when active antihypertensive therapy was required.

\section{Discussion}

The place of $\alpha$-adrenoceptor blocking drugs in the treatment of essential hypertension is not yet established. Brownlee (1966) pointed out that, logically, drugs acting in this way ought to provide the most effective means of lowering blood pressure, but that most known $\alpha$-blocking drugs had other pharmacological actions which prevented their longterm use in this condition. Although indoramin has important pharmacological properties apart from its $\alpha$-adrenoceptor-blocking activity, it has been possible to treat some patients with essential hypertension for many months without untoward effects and with satisfactory blood pressure control. However, although sedation did not occur with single $20 \mathrm{mg}$ oral doses of indoramin (Royds et al., 1972), a proportion of patients on higher and continuous dosage reported this symptom.

The controlled investigation of the effects of desipramine suggest that the interaction demonstrated with guanethidine, bethanidine (Mitchell et al., 1970) and clonidine (Briant et al., 1973) in which a marked reversal of the antihypertensive effect occurs, does not arise with indoramin. In fact there was a slight additive effect with the addition of desipramine, which may be due to its $\alpha$-adrenoceptor-blocking activity (McCullough and Story, 1972).

Mitchell et al. (1970) found that the reversal of the antihypertensive effects occurred within 2 days in patients on guanethidine, and within a few hours on bethanidine and debrisoquinone, when treated with desipramine in a dose of $25 \mathrm{mg} 8$ hourly. Moreover it was seen in every patient so treated. Four or five patients on clonidine showed reversal within a week of the introduction of desipramine (Briant et al., 1973).

It may be argued that, since there was no change in blood pressure of the patients for at least 5 weeks following withdrawal of indoramin, it is unlikely that a reversal by desipramine would be seen within 10 days. However, a prolonged period of normotension follows withdrawal of guanethidine in many cases (Dollery, 1967) although reversal with desipramine is rapid. While the possibility of a later reversal of indoramin's hypertensive effect has not been excluded, this study suggests that, where a patient with essential hypertension requires treatment with a tricyclic antidepressant drug, indoramin may be of value in the control of hypertension.

The delay in relapse of hypertension in all our patients studied after withdrawal of effective indoramin treatment illustrates an important question in the assessment of antihypertensive drugs. This effect has been reported in extensive studies with long established antihypertensive agents with different modes of action (Page and Dustan, 1962; Perry et al. 1966; Thurm and Smith, 1967) and a $\beta$-adrenoceptor blocking drug (Persson and Ulrich, 1973).

It is unlikely that there is prolonged receptos blockade following indoramin withdrawal as othes evidence of adrenergic blockade, such as impaire sexual function, disappears within a few days of discontinuation. Baroreceptor resetting has been demonstrated in dogs with renogenic hypertension (McCubbin, Green and Page, 1956) and Page and Dustan (1962) suggested that this mechanism could account for their findings of a persistent effect in nine out of the twenty-seven patients whose drug treatment was discontinued in their study. Prichard and Gillam (1969) suggested that the antihypertensive effects of $\beta$-adrenoceptor blocking drugs might be due in part to a change in baroreceptor activity. Such a long term change would by its very nature be difficult to confirm, but the time course of indoramin's action would be consistent with it. That the effect is dependent on the previous duration of treatment with indoramin received some support from the finding, in patient 3 , that withdrawal of indoramin after 8 weeks' effective treatment was followed by a rise in blood pressure to pretreatment levels within 1 week. A similar rise after discontinuation took 7 weeks to occur when the same patient had been maintained on the drug for 6 months.

If such periods of prolonged normotension do in fact follow effective antihypertensive drug therapy, then the use of crossover designs in the assessment of new agents, such as one recently used to assess 
indoramin (Lewis et al., 1973), must be questioned. It is evident that if the criterion for antihypertensive efficacy is to be based on the difference between the effect of active drug and identical placebo, periods of active treatment must be followed by prolonged wash-out intervals. The duration of such placebo wash-out must be determined separately for each patient by an increase in blood pressure towards pretreatment levels.

A therapeutic implication of the effect, as pointed out by Page and Dustan (1962), is that after long periods of effective treatment regular attempts should be made to reduce or stop antihypertensive drugs and thereby avoid untoward effects.

In conclusion, clinical experience with indoramin has demonstrated that $\alpha$-adrenoceptor blockade with indoramin may be of value in the management of essential hypertension. The absence of troublesome tachycardia may be due to the drug's associated cardioinhibitory activity (Alps et al., 1972).

Although sedation at antihypertensive doses limited its use in some patients, the lack of reversal of its antihypertensive effects by treatment with desipramine for a 10-day period suggests that it may be a valuable drug in hypertensive patients requiring tricyclic antidepressant therapy.

\section{Acknowledgments}

We thank John Wyeth \& Brother, Ltd, for financial support and supplying indoramin, and Geigy Pharmaceutical, Ltd, for providing desipramine.

\section{References}

Alps, B.J., Hill, M., Johnson, E.S. \& Wilson, A.B. (1972) Quantitative analysis on isolated organs of the automatic blocking properties of indoramin hydrochloride (Wy 21901). British Journal of Pharmacology, 44, 52.

Boakes, A.I., Prichard, B.N.C. \& TeOH, P.C. (1972) $\alpha$ Adrenoceptor inhibition from indoramin in man. British Journal of Pharmacology, 44, 378.

BRIANT, R.H., ReID, J.L. \& DolleRY, C.T. (1973) Interaction between clonidine and desipramine in man. British Medical Journal, 1, 522.

Brownlee, G. (1966) Drugs which lower blood pressure. Transactions of the Medical Society of London, 82, 103.
Collis, M.G. \& AlPS, B.J. (1973) The evaluation of the $\alpha$-adrenoceptor blocking action of indoramin, phentolamine and thymoxamine on the rat and guinea-pig isolated mesenteric vasculature and aortic spiral preparations. Journal of Pharmacy and Pharmacology, 25, 621.

DollerY, C.T. (1967) Drugs and the regulation of blood pressure. In: Modern Trends in Pharmacology and Therapeutics, Volume 1, p. 310. Butterworths: London.

Lewis, P.J., George, C.F. \& Dollery, C.T. (1973) Clinical evaluation of indoramin, a new antihypertensive agent. European Journal of Clinical Pharmacology, 6, 211.

McCubbin, J.W., Green, J.H. \& PAge, I.H. (1956) Baroceptor function in chronic renal hypertension. Circulation Research, 4, 205.

McCullough, M.W. \& Story, D.F. (1972) Antagonism of noradrenaline and histamine by desipramine in the isolated artery of the rabbit ear. British Journal of Pharmacology, 46, 140.

Mitchell, J.R., Cavanaugh, J.H., Arias, L. \& OAtes, J.A. (1970) Guanethidine and related agents. III Antagonism by drugs which inhibit the norepinephrine pump in man. Journal of Clinical Investigation, 49, 1596.

Page, T.H. \& Dustan, H.P. (1962) Persistence of normal blood pressure after discontinuing treatment in hypertensive patients. Circulation, 25, 433.

Perry, H.M., Schroeder, H.A., Catanjaro, F.J., MooreJoNES, D. \& CAMEL, G.H. (1966) Studies in the control of hypertension. VIII Mortality, morbidity and remissions during twelve years of intensive therapy. Circulation, 33, 958.

Persson, I. \& Ulrich, J. (1973) Treatment of hypertension with a new $\beta$-blocking agent, pindolol (Visken). European Journal of Clinical Pharmacology, 6, 217.

Prichard, B.N.C. \& GillaM, P.M.S. (1969) Treatment of hypertension with propranolol. British Medical Journal, 1, 7.

RoYDS, R.B. (1972) Initial clinical experience with indoramin, a new antihypertensive agent. British Journal of Pharmacology, 44, 379.

Royds, R.B., Coltart, D.J. \& LockharT, J.D.F. (1972) Pharmacological studies of indoramin in man. Clinical Pharmacology and Therapeutics, 13, 380.

Simpson, F.O. \& WAAL-MANNING, H.J. (1971) Hypertension and depression: interrelated problems in therapy. Journal of The Royal College of Physicians of London, 6, 14.

ThURM, R.H. \& SMITH, W.M. (1967) On resetting of 'barostats' in hypertensive patients. Journal of the American Medical Association, 201, 301.

VARIAVA, D.H. \& TURner, P. (1973) The $\alpha$-adrenoceptor blocking effect of indoramin on human isolated smooth muscle. Journal of Pharmacy and Pharmacology, 23, 629. 